\title{
Studies on Relevant Problems in Reading and Writing Teaching of College English Major
}

\author{
Li Hongbin \\ Foreign Language Department \\ Jilin Business and Technology College \\ Changchun, China \\ 182076127@qq.com
}

\begin{abstract}
Reading and writing have a large proportion in college English major teaching, because it is vital for students to master the comprehensive competence in English use. The condition of reading and writing teaching has a direct relationship with the quality of college English major teaching. However, there are a series of problems in current reading and writing teaching. This article mainly explores the current situation and the existing problems in reading and writing teaching of college English major due to text-based teaching for years and points out strategies and methods on the basis of the new curriculum requirements and strongly appeals for qualityoriented teaching, it aims to exert and positive effect on the ongoing college English reform so that improve students' comprehensive English ability.
\end{abstract}

Keywords-College English major, Reading and writing teaching, problems and strategies

\section{INTRODUCTION}

Since entering the 21st century, the relationship between China and other countries is becoming more and more close and the exchange of politics, economy, military and culture among them is becoming more and more frequent with China entering WTO and a series of international activities held in China, including the Beijing Olympics and Shanghai World Expo. A large number of high-quality English talents in reading and writing field are needed by our society. The situation of our country's college English teaching cannot keep up with the development of the world. Thus, executing quality teaching roundly has been widely raised.

\section{The Current Situation OF REAding AND Writing TEACHING IN COLLEGE ENGLISH MAJOR}

\section{A. Test-based teaching for years makes the college English teaching only for all kinds of tests, not for knowledge.}

In the practical teaching work, the phenomenon of testbased teaching is almost prevail and some colleges just focus on passing rate and excellent rate while they neglect the training of students' application ability, and this caused college students had poor ability to apply English including applying reading and writing into practice. For example, in the TEM-4, the average scores of writing can reflect that students' real language level is at a low point for a long time, and some graduates of English major who have succeeded in passing
TEM-8 even performed badly in their real job. In a long period in our country, the purpose of learning English is not for practical application, but for examinations. A college student, has learned English at least 12 years, during which can make a person almost completely master a language, even if a foreign language. But it is a different story in our country. Many people know Chinese students' English speaking and listening abilities are not satisfying due to the lack of language environment and other factors. They always neglect the problems in reading and writing. After being admitted by colleges or universities, many English majors will find they are not able to speak English very well and cannot understand the content of their listening teaching materials. In fact, their reading and writing abilities also need to improve greatly though they have received certain training in high schools, and it is not enough at all.

The TEM do have a negative effect on the teaching of English major. It leads to the result that students overweight the exams and neglect to train the real English ability. Meanwhile, the society overemphasizes the English level of English major students and many employers only care whether or not an English major graduate have a certificate of TEM-4 or TEM-8. They just think he or she is not qualified if the person failed to pass one of the two exams and they take the exam result as the scale of the recruiting. So the only purpose for many English major students is to pass the two exams so that they may spend too much time and energy in preparing the tests while they should develop a comprehensive English ability during the precious college time. They research the question style of the exams and just focus on them and neglect all other study tasks. For example, they may choose to recite dozens of model essays of writing so that they get a satisfying grade or they may recite lots of humanistic knowledges of English-speaking countries, some of which may be chosen in the exams. Some of them even adopted improper means such as cheating in the exams. These activities will finally affect to grasp an overall English ability[1].

\section{B. The pattern of teaching is relatively simple and outmoded}

Language learning should be as enjoyable as possible so that students can study enthusiastically. However, many students cannot feel the pleasure at all. The simple and outmoded teaching patterns may be explained as one of the reasons why many students lack the motivation for learning. For years, "Grammar-translation Method" taking the teachers 
as the center in the course of teaching has dominated the English teaching in China. Up to now, this situation has not been changed yet. Studies show that $70 \%$ of college professionals have admitted that the main method in teaching is remaining “Grammar-translation Method”. They explained that the communication method has been considered to be better than grammar-translation method, however, for various reasons, such as the students' real ability, the teachers 'language competence, the limited time in classroom, the number of the students and the pressure of exams, both teachers and students considered that the "Grammar-translation Method" is more practical.

Therefore, college English teaching has always been the teacher's "One-man Show", while the students are just like the audience. This single teaching pattern has deprived students' opportunities of using language and habits of generating creative thinking.

\section{C. "Time consuming and Inefficient" in reading and writing teaching}

Moreover, the limitation of the reading and writing textbooks has also contributed to the inefficient results of teaching. Textbooks on reading and writing for English majors have focused on informational, interestingness and forwardlooking, with a broad array of topics and abundant contents, which involved in cultural custom, ethics and morality, information technology, scientific teaching and social focus, etc., but there are still certain limitations with them. The limitations are mainly reflected in the contents of textbooks which focus on enlarging students' vocabulary, lacking the gradualness and the increasing of difficulty in reading is not obvious, and students are unfulfilled in the course of reading. Besides, as the timeliness of the textbooks' compilation, many articles on high-tech and hot-spots of the society are no longer attractive for students over time.

In addition, the class size is so large that there are difficulties of interaction between teachers and students. Asking questions by teachers is not only the platform of communication between teachers and students but also a necessary means of interaction between them. Asking questions in class really plays a crucial role in language teaching. Yet in the course of reading and writing teaching of college English, asking and answering questions and interaction between teachers and students have not been completed effectively due to the limitation of class size and hour. So it is hard to build an effective communication of teachers and students, and separate teaching from learning. If things continue in this way, students may feel bored in class and sit at the back of classroom to do their own things. Even if in an English class which contains hundreds of students, the teacher hardly attract students' attention for long though using modern teaching tools[2].

\section{Students' inertness and dependence}

Many college students are not willing to work hard on reading and writing, which needs to spend time in the classroom or library. In addition, final exams are just basic language tests that few students would fail to pass. Thus, plenty of students don't have the habits of previewing before class, writing notes in class, or reviewing the lesson after class, let alone practicing writing in their spare time. Even in class, it is impossible for the teachers to check every student's learning situation because of the large number of them. Therefore, students' inertness and dependence are also problems in reading and writing teaching. Moreover, the quality of teachers needs to be improved gradually. This doesn't mean that college English teachers are qualified, but knowledge is infinite. As is known, college students do have certain English competences, English majors or non-English majors, since they all succeed in passing the college entrance examination. Only courses given by high level teachers can attract their attention, making them keep active to have a better interaction with teachers, reducing their inertness and dependence[3].

\section{StRATEgIES OF SOLVING THE PROBLEMS IN ENGLISH READING AND WRITING TEACHING}

\section{A. Extending the field of vision and enriching the teaching contents}

Aiming at the limitation of contents of the textbooks, the teachers need to do a good job of material collection before class for a better teaching result. In the course of collecting materials, teachers may find out subjects that easily attract students' attention, such as videos, audios, text and picture materials, or movie clips and cultural background knowledge concerning the subject. Teachers can show these materials to students by using multi-media teaching aid before class to motivate students' imagination so that they can be brought into the class' atmosphere. Teachers can design more teaching activities to increase students' participation in class. For example, before interpreting an article, the teacher can ask students to think about one or two questions concerning the article and let them write down their views on the paper or ask them to prepare a PPT relating to a real event in turns and show their presentation on the next class. The course of preparing is also a course of initiative reading and writing. It not only practices students' reading and writing skill, but also enlivens the classroom atmosphere. And the subject is related to the article they are going to learn, so this is good for introducing the article.

The key to make students involved in the class is to students come alive, and make them become interested in the class. One of the objectives of the college English teaching is to train students to use language comprehensively. Listening and reading are considered to be the course of the input and accumulation of language. While speaking and writing are the courses of the output and practical use of the language. Moreover, listening and speaking, and reading and writing, should not be divided into two groups when studying English. In class of listening and speaking, some contents of reading and writing can be arranged properly, and the class of reading and writing should not be the silent class. In the course of teaching, teachers should try their best to make the teaching materials vivid and lively, make it integrate with reality. For example, teachers can guide students to perform the scenes of the teaching materials group by group so that stimulating students ' interests and understanding the contents of the 
teaching materials better. In this way, not only the students' speaking ability, but also their understanding can be improved greatly[4].

Besides, encouraging students to use the abundant network resources is also what teachers need to do. In this way, they can develop students' independent study ability. Thus, students' horizons can be broadened, the limitation of textbooks can be broken, and efficient and convenient teaching platform can be built. Nowadays, network information are developing in an unexpected rate and the information form has diversified characteristics, including text and picture, data, video, etc., and these can help students study languages through diversified forms, not only in listening and speaking, but also in reading and writing. Moreover, teachers and students can use E-mail, QQ group, Wechat, and Microblog to communicate and discuss, executing to answer questions and instructing online and sharing information resources.

\section{B. Building multiple teaching patterns and increasing the interaction between teachers and students.}

In the course of classroom teaching, teachers should change the previous teaching pattern which takes teachers as the center and build the student-oriented teaching pattern, bringing students into the classroom teaching. In terms of knowledge interpretation, teachers should explain precisely. So teachers need to understand teaching materials thoroughly and carefully, concentrate on crucial points and leave the rest to students for their independent studying. By doing such things, not only the utilization of classroom time can be increased, but students' independent studying ability can be improved as well. The precise interpretation means that teachers should teach students the methods of English reading and writing in simple but refined language. Corder, a linguist, once claimed in his works that, "Effective language teaching should not disobey the natural course and impede the learning, but help and benefit learning, should not make students fit teachers and teaching materials, but let them to fit the former. " therefore, students' positive involvement is considered to be crucial in learning languages.

Teachers can design a brief content of "answer the questions”, making problems be solved immediately. Furthermore, when interpreting the contents of the article, the teacher can add some topics which are fresh, popular and close to the real life. Taking some things that are attractive to students as the carrier, then the contents will be considered to be fresher and knowledge points of the language will be absorbed easily and effectively. This can solve the problem of shortage in teaching contents[5].

\section{Breaking through the limitation of microcosmic language points and analyzing articles in a text scale.}

Every article in reading and writing courses of English major is an organic whole and every text has its specific writing structure. In order to make students can grasp the article on the whole and improve their own writing according to the learned article' s structure after learning it, teachers should lead students to beyond the scope of sentence research, focus their attention on a higher level of link of sentences and paragraphs, and conduct a structure and text analysis instead of just focusing on interpreting those scattered knowledge points. After the text analysis along with their teachers, students can not only understand the article's basic meaning, but also understand and grasp its deeply connotation, thus summarizing its main idea and writing skill and obtaining relevant knowledge of cultural background and professional field through the article. In this way, after learning every article, students can not only obtain more western culture and language knowledge, but grasp the new writing skills[2].

\section{Forming an effective evaluation system and prompting students' positivity and creativity}

Successful teaching practice is always connected with an effective evaluation system, so is the reading and writing teaching of English major. Using the evaluation system properly can not only make teachers get feedback from students, but also prompt the students' positivity and creativity effectively. Thus, teachers should not neglect the forming of evaluation system in the course of reading and writing teaching To solve the problem of large number of students and difficulty in operating, teachers can supervise the students' learning situation and get feedback of teaching in time through the platform of multi-media network teaching system. For example, the New Vision College English Network Learning System, can record the time of students' independent study and get a feedback to students' practice so that helping teachers learn students' study situation and find out the problems in the course of learning. Besides, in the course of forming the evaluation system, teachers can introduce the evaluation method of students' self-evaluation and mutual evaluation to enhance the students' sense of participation and selfimprovement and motivate students' study positivity[6].

\section{CONCLUSION}

In a word, there are lots of problems in reading and writing teaching of English major in college under current teaching pattern. This article explores the problems in current teaching practice by analyzing the situation of reading and writing of English major in college and raises strategies of solving the problems. The author thinks the current situation of reading and writing teaching of English major can be greatly improved through motivating students' positivity, changing traditional teaching pattern and adopting multiple class organization and evaluation system.

\section{REFERENCES}

[1] Yuhongwei, Chenbao, Huangwei, "Motivation and Positivity in College English Class” [J]. "Journal of Xinjiang Education College”, 2006. Vol 22, 2: 79-81.

[2] Guoli, Chenmingrui, Wanglang, "Improving English Reading Ability by Using of Text Analysis” [J]. "Journal of Zhongshan University”, 2006, Vol 26, 7:135-137.

[3] Linyun, Songyanping, "Execution of Forming Evaluation System in College English Teaching”, [J]. “Adult Education in China”. September, 2006: 169-170.

[4] Zhang Guangjun, “Teaching Relationship in Multiple Version”, [J "Study on Teaching” 2003:6 
[5] Yang Xueyan, "Studies on Foreign Language Teachers' Class Strategies”.[J ],”Foreign Language Teaching and Studying” 2003: 1.
[6] Du Fuxing, "Motivation and Maintenance of English Studying". [J ] “Foreign Language Teaching”. 2003:4. 